\title{
A Fuzzy Optimization Approach Designed for Calibrating the Fuel Injection Parameters of Turbocharged Diesel Engine
}

\author{
Meng Xia, Changlu Zhao, Fujun Zhang*, Ying Huang and Miandun Huang \\ School of Mechanical Engineering, Beijing Institute of Technology, Beijing 100081, China \\ ${ }^{*}$ Corresponding author
}

\begin{abstract}
In order to enhance the performance of turbocharged diesel engine working at plateau, a fuzzy optimization approach for calibrating the fuel injection parameters is proposed. Simulation model of a turbocharged intercooler diesel engine is built on the GT-POWER platform. Through analyzing the effect of fuel injection parameters on surge, turbine speed and turbine inlet temperature, the fuzzy optimization algorithm is set up on MATLAB/simulink platform. Fuzzy rules are developed according to the relationship between injection parameters and constraint conditions. Then the co-simulation between MATLAB and GT-POWER with four different initial conditions are carried out at the operation point of $4000 \mathrm{~m}, 2100 \mathrm{r} \cdot \mathrm{min}^{-1}$. Simulation results show that the fuzzy optimization algorithm is feasible. No matter where the initial point locates, the result can converge to the optimum point. Besides, the rate power of the diesel engine is improved by $21 \%$ compared to that of the original, and brake specific fuel consumption declines $10 \%$ compared to that of the original.
\end{abstract}

Keywords-diesel engine, power recovery at plateau, fuzzy algorithm, fuel injection parameters

\section{INTRODUCTION}

The air density has a sharp decrease at high altitude area. Diesel engine which can operate well in the sea level may not work properly at the plateau environment. The engine performances, such as power, economy and emission, may be deteriorated a lot at the plateau environment [1-2]. Besides, the turbocharger may have the trend of surge or over speed [3-4].

Some researchers have found that adjusting the injecting timing can help to increase the engine power at plateau [2]. Zhu et al. [3] recovered the rated power of a v6 diesel engine to $89.7 \%$ of the plain value by adjusting fuel injection parameters. As the injection advanced, the combustion process moves forward, which leads to the drop of the rotated speed of the turbocharger and turbine inlet temperature [2-3]. But over advanced injection angle will lead to more power consumption at compression stroke which may lead to power decreasing, and the peak pressure in cylinder will also be increased [5]. Ref.[6] shown that with the increasing of fuel injection mass, the engine power, rotate speed of the turbocharger, peak pressure in cylinder, and turbine inlet temperature are all increased.

Fuel injection mass $\left(m_{f u e l}\right)$ and fuel injection advanced angle $(\alpha)$ are two major factors that affect diesel engine performance at high altitude. So it is very important to find the proper combination of these two parameters. However, the engine is a nonlinear and complex system which makes it difficult to do this job. Genetic algorithm has been used to optimize the fuel injection parameters in Ref.[7] and Ref.[8], but it needs to choose the proper penalty parameters according to different working conditions.

As the engine model is considered to be complicated, nonlinear and discontinuous, the traditional methods are not capable for the optimization of fuel injection parameters. Fuzzy optimization method is very suitable to solve these problems. Fuzzy theory has better control performance and robustness [9][10]. It has been widely used in the aspect of engine modeling, optimization and control in recent years [11-15]

In this paper, our research on calibration of fuel injection parameters using fuzzy optimization method for diesel engine working at plateau is presented. The main features of the work are as follows: first, a simulation model of the 6-cylinder Vtype intercooler turbocharged diesel engine is built based on experimental data; second, the optimization aim is shown, and the boundaries are simplified; third, fuzzy optimization method is designed. The main purpose of this paper is to propose a fuzzy optimization method to calibrate the fuel injection parameters and enhance the performance of diesel engine working at plateau.

\section{Simulation MODEL}

The research is based on a 6-cylinder V-type turbocharged intercooler diesel engine, and the key parameters are shown in Table 1.

TABLE I. TABLE TYPE STYLES

\begin{tabular}{|c|c|}
\hline Parameters & Value \\
\hline Bore $/ \mathrm{mm}$ & 132 \\
\hline stroke $/ \mathrm{mm}$ & 145 \\
\hline Compression ratio & 17 \\
\hline Rate power $/ \mathrm{kw}$ & $330.5 @ 2100 \mathrm{r} / \mathrm{min}$ \\
\hline Maximum torque $/(\mathrm{N} \cdot \mathrm{m})$ & $1987 @ 1300 \mathrm{r} / \mathrm{min}$ \\
\hline$p_{\max } / \mathrm{MPa}$ & 14.5 \\
\hline Maximum $\mathrm{T}_{\mathrm{ex}} /\left({ }^{\circ} \mathrm{C}\right)$ & 720 \\
\hline Maximum $\mathrm{n} /(\mathrm{r} / \mathrm{min})$ & 100,000 \\
\hline
\end{tabular}

The simulation model is built on GT-POWER platform. The combustion process is described by using a zero dimension predictive combustion model based on neural network $(\mathrm{NN})$ 
and three Wiebe functions. Five operation parameters - the air temperature and pressure of the intercooler outlet, the fuel injection mass, the fuel injection advanced angle and engine speed are chosen as the input parameters of the NN. These five parameters are related to the combustion process. Nine parameters of the three Wiebe functions are chosen as the output parameters of the NN. The training data of $\mathrm{NN}$ is obtained from experiments in a plateau environment simulation cabin. The experiment covers the engine speed ranging from $1000 \mathrm{r} / \mathrm{min}$ to $2100 \mathrm{r} / \mathrm{min}$, load ranging from $10 \%$ to $100 \%$, fuel injection advanced angle ranging from $-16.5^{\circ}$ to $-21.5^{\circ}$, $4000 \mathrm{~m}$ altitude, and intercooler temperature ranging from $40{ }^{\circ} \mathrm{C}$ to $90{ }^{\circ} \mathrm{C}$. The main procedures to built this combustion model are shown in Ref.[3], Ref. [16] and Ref. [17]. Figure 1, Figure 2 and Figure 3 show the comparison of peak pressure in cylinder $\left(p_{\max }\right)$, turbine inlet temperature $\left(T_{e x}\right)$, engine power $(P)$ and air mass flow between experiment data and simulation results. It can be seen that the tendency of the simulation results is correct and the maximum errors are all less than $7 \%$.

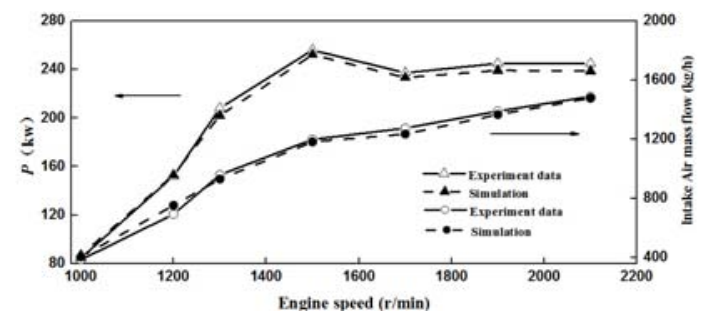

FIGURE I. comparison of Peak pressure in-cylinder.

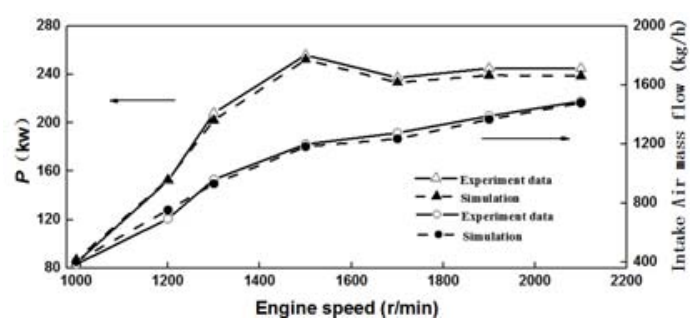

FIGURE II. COMPARISON OF POWER AND AIR MASS FLOW RATE.

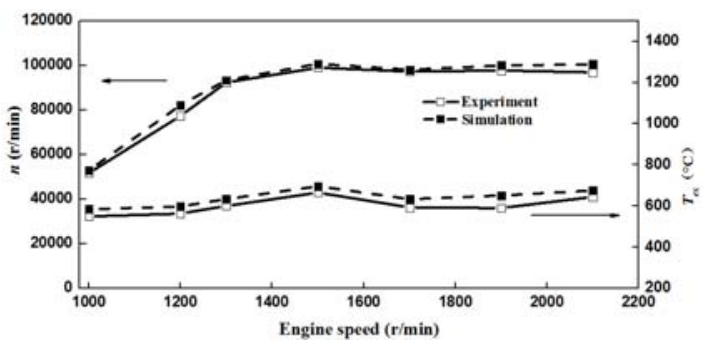

FIGURE III. COMPARISON OF TURBOCHARGER SPEED AND TURBO INLET TEMPERATURE.

\section{OPTIMIZATION AIM AND CONSTRAINTS}

\section{A. Optimization Aim}

The optimization aim can be expressed in (1) and the operating boundaries are shown in (2)-(5). Where $\vec{x}$ is a twodimensional vector representing the combination of fuel injection mass and fuel injection advanced angle. $P(\overrightarrow{\mathrm{x}})$, $p_{\max }(\overrightarrow{\mathrm{x}}), T_{e x}(\overrightarrow{\mathrm{x}})$ and $n(\overrightarrow{\mathrm{x}})$ represent engine power, peak pressure in cylinder, turbine inlet temperature and rotate speed of turbocharger respectively. $S$ represents the measure of surge trend. It can be defined as can be seen from Figure 4. The line OA is approximate $5 \%$ margin away from the surge line. The slope of OA is $S_{0}$. B is an operating point, and the slope of line OB is $S$. When $S>S_{0}$ or $S<0$, it can be judged that the surge phenomenon occurs at point B. The definition of $S$ and $S_{0}$ are shown in (6)-(7).

$$
\begin{gathered}
p_{\max }(\overrightarrow{\mathrm{x}}) \leq 14.5 \mathrm{Mpa} . \\
T_{e x}(\overrightarrow{\mathrm{x}}) \leq 720^{\circ} \mathrm{C} .
\end{gathered}
$$

$$
n(\overrightarrow{\mathrm{x}}) \leq 100000 r\left[\mathrm{~min}^{-1} .\right.
$$

$$
S \leq S_{0}
$$

$$
S_{0}=\frac{p r_{A}-p r_{0}}{q_{A}-q_{0}}
$$

$$
S=\frac{p r_{\vec{x}}-p r_{0}}{q_{\vec{x}}-q_{0}}
$$

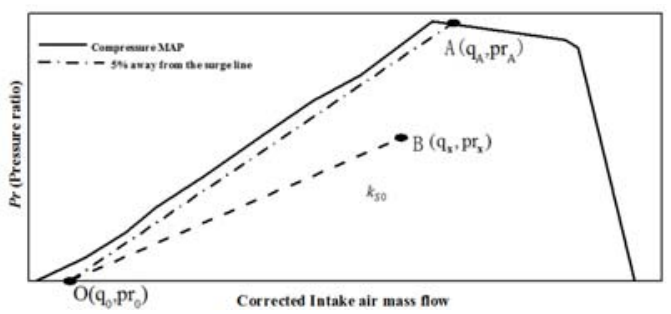

FIGURE IV. DEFINITION OF SURGE.

\section{B. Transformation of Boundary Conditions}

In order to express how far the constraint variables deviating from their limited values in a unified way, Equation 
(2)-(4) are transformed into 'violation degree' form which are shown in (8)-(11). tc is defined in (12) and represents the turbine total constraint parameter. When $t c$ is greater than 1 , it means there may be too much exhaust energy, and $T_{e x}$ or $n$ or $S$ may have exceed the limit.

$$
\begin{gathered}
h_{1}(\vec{x})=p_{\max }(\vec{x}) / 14.5-1 . \\
h_{2}(\vec{x})=T_{e x}(\vec{x}) / 720-1 . \\
h_{3}(\vec{x})=n(\vec{x}) / 100,000-1 . \\
h_{4}(\vec{x})=S / S_{0}-1 . \\
t c=\max \left(h_{2}(\vec{x}), h_{3}(\vec{x}), h_{4}(\vec{x})\right) .
\end{gathered}
$$

\section{Parameter Influence Analysis}

It is obviously that more fuel means more energy. With the increasing of fuel injection mass, the peak pressure in cylinder, turbine inlet temperature and rotate speed of turbocharger are all increased. With the increasing of fuel injection advanced angle, the peak pressure in cylinder increases while the turbine inlet temperature and rotate speed of turbocharger decreases.

Simulation is going on to analyze the influence of fuel injection parameters on $S$. The operating point of simulation is set at $2100 \mathrm{r} / \mathrm{min}, 4000 \mathrm{~m}$ altitude. As can be seen from Figure 5, the $S$ increases with the increasing of fuel injection mass and decreases with the increasing of fuel injection advanced angle. As the injection advanced or fuel injection mass reduced, the exhaust energy decreases, which leads to the drop of $S$.

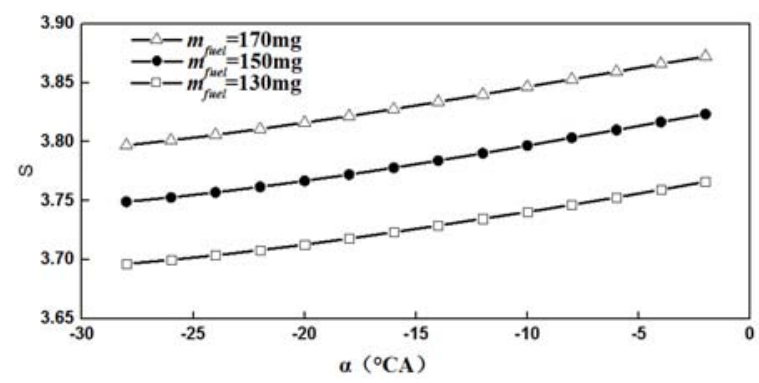

FIGURE V. IMPACT PRINCIPLES OF FUEL INJECTION PARAMETERS ON SURGE.

\section{Design OF FuZZY Optimization Method}

The Fuzzy optimization method is designed based on the fuzzy logic controller, and its structure is shown in Figure 6. The input parameters include $p_{\max }, T_{e x}$ and $n$, and the output parameters include $m_{f u e l}$ and $\alpha$. The engine is such a nonlinear system making it hard to express the relationship between input and output clearly. That is why the 'Mamdani' fuzzy reasoning method is used here. The universe of the input and output are all $[-1,1]$. In Figure $6, \Delta$ it represents the variation of fuel injection advanced angle and $\Delta \mathrm{im}$ represents the variation of fuel injection mass. $k_{1}$ and $k_{2}$ are quantitative factors; $k_{3}$ and $k_{4}$ are scale factors. Besides, Center-of-Gravity method [15] is used for defuzzification in this paper.

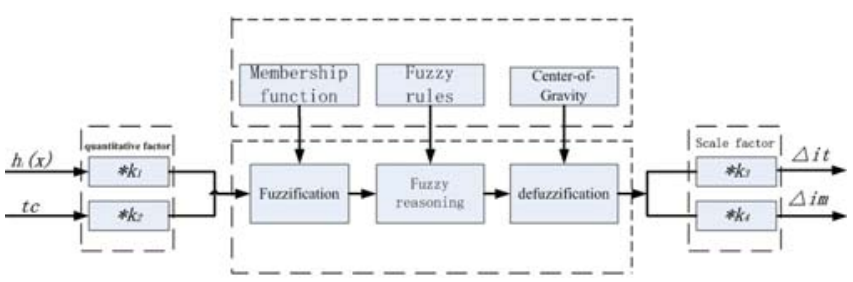

FIGURE VI. STRUCTURE OF FUZZY OPTIMIZATION METHOD

\section{A. Membership Functions}

The membership function is used for decomposing the input or output of a system into one or more fuzzy sets. The design process of the membership function is subjective. And in this paper, the triangular shaped membership function, which is used commonly, are selected for the input and output. Fuzzy set definitions are shown in Figure 7. Table 2 shows the linguistic qualifiers. To reduce the range of blind zone near zero, fuzzy sets near zero are subdivided in [-0.01, 0.01]. The fuzzy set $\{\mathrm{NB} 、 \mathrm{NM} 、 \mathrm{NS} 、 \mathrm{NZ} 、 \mathrm{PZ} 、 \mathrm{PS} 、 \mathrm{PM} 、 \mathrm{~PB}\}$ represents \{Negative Big, Negative Middle, Negative Small, Negative Zero, Positive Zero, Positive Small, Positive Middle, Positive Big\}.

TABLE II. TABLE TYPE STYLES

\begin{tabular}{|c|c|c|c|c|c|c|c|c|}
\hline \multirow{2}{*}{$\begin{array}{c}\text { Fuzzy } \\
\text { set }\end{array}$} & \multicolumn{7}{|c|}{ Universe } \\
\cline { 2 - 9 } & $\mathbf{- 1}$ & $-\mathbf{0 . 6 7}$ & $-\mathbf{0 . 3 4}$ & $-\mathbf{0 . 0 1}$ & $\mathbf{0 . 0 1}$ & $\mathbf{0 . 3 4}$ & $\mathbf{0 . 6 7}$ & $\mathbf{1}$ \\
\hline NB & 1 & 0 & 0 & 0 & 0 & 0 & 0 & 0 \\
\hline NM & 0 & 1 & 0 & 0 & 0 & 0 & 0 & 0 \\
\hline NS & 0 & 0 & 1 & & 0 & 0 & 0 & 0 \\
\hline NZ & 0 & 0 & 0 & 1 & 0 & 0 & 0 & 0 \\
\hline PZ & 0 & 0 & 0 & 0 & 1 & 0 & 0 & 0 \\
\hline PS & 0 & 0 & 0 & 0 & 0 & 1 & 0 & 0 \\
\hline PM & 0 & 0 & 0 & 0 & 0 & 0 & 1 & 0 \\
\hline PB & 0 & 0 & 0 & 0 & 0 & 0 & 0 & 1 \\
\hline
\end{tabular}




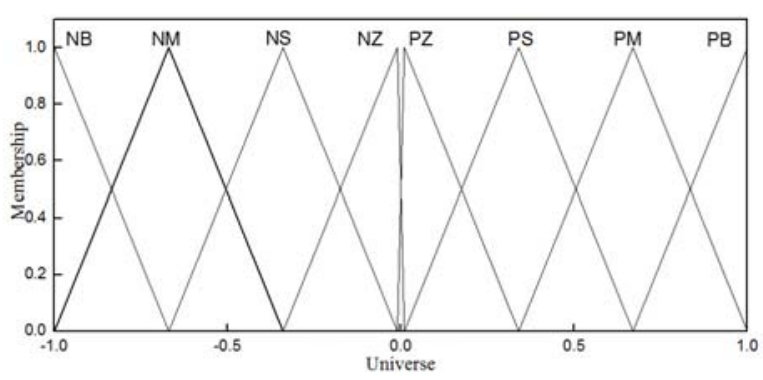

FIGURE VII. MEMBERSHIP FUNCTION.

\section{B. Fuzzy Rules}

According to the analysis parameter influence, the fuzzy rules are made in this part. The relationship between input parameters and output parameters is shown in Figure 8, Line I (or Line II) denotes the relationship between $m_{f u e l}$ and $\alpha$ when $p_{\max }($ or $t c$ ) reaches its maximum value. The intersection $\mathrm{R}$ is the optimum value. The area A means that $p_{\max }$ has not reached the limit and $t c$ has reached the limit. The characteristic of area $\mathrm{B}, \mathrm{C}$ and $\mathrm{D}$ can be analyzed in the same way.

According to the analysis mentioned above, the fuzzy rules of $\Delta \mathrm{IT}$ and $\Delta \mathrm{IM}$ are made as shown in Table 3 and Table 4 respectively, Where $\Delta \mathrm{IT}$ and $\Delta \mathrm{IM}$ represents the variation of $\alpha$ and $m_{\text {fuel }}$ before scaling respectively. '-'means undefined.

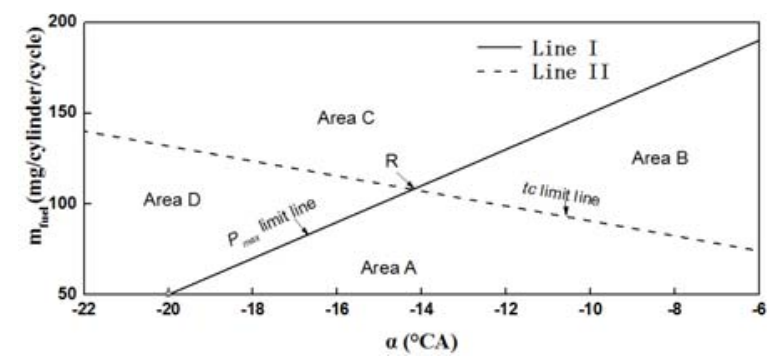

FIGURE VIII. RELATIONSHIP BETWEEN INPUT AND OUTPUT PARAMETERS.

TABLE III. FUZZY RULES OF $\triangle I T$

\begin{tabular}{|c|c|c|c|c|c|c|c|c|}
\hline \multirow{2}{*}{ tc } & \multicolumn{7}{|c|}{$\boldsymbol{P}_{\max }$} \\
\cline { 2 - 9 } & $\mathbf{N B}$ & $\boldsymbol{N M}$ & $\boldsymbol{N S}$ & $\boldsymbol{N Z}$ & $\boldsymbol{P Z}$ & $\boldsymbol{P S}$ & $\boldsymbol{P M}$ & $\boldsymbol{P B}$ \\
\hline $\mathrm{NB}$ & - & - & - & - & $\mathrm{PZ}$ & $\mathrm{PS}$ & $\mathrm{PM}$ & $\mathrm{PB}$ \\
\hline $\mathrm{NM}$ & - & - & - & - & $\mathrm{PZ}$ & $\mathrm{PS}$ & $\mathrm{PM}$ & $\mathrm{PM}$ \\
\hline $\mathrm{NS}$ & - & - & - & - & $\mathrm{PZ}$ & $\mathrm{PS}$ & $\mathrm{PS}$ & $\mathrm{PS}$ \\
\hline $\mathrm{NZ}$ & - & - & - & - & $\mathrm{PZ}$ & $\mathrm{PZ}$ & $\mathrm{PZ}$ & $\mathrm{PZ}$ \\
\hline $\mathrm{PZ}$ & $\mathrm{NZ}$ & $\mathrm{NZ}$ & $\mathrm{NZ}$ & $\mathrm{NZ}$ & - & - & - & - \\
\hline $\mathrm{PS}$ & $\mathrm{NS}$ & $\mathrm{NS}$ & $\mathrm{NS}$ & $\mathrm{NZ}$ & - & - & - & - \\
\hline $\mathrm{PM}$ & $\mathrm{NM}$ & $\mathrm{NM}$ & $\mathrm{NS}$ & $\mathrm{NZ}$ & - & - & - & - \\
\hline PB & $\mathrm{NB}$ & $\mathrm{NM}$ & $\mathrm{NS}$ & $\mathrm{NZ}$ & - & - & - & - \\
\hline
\end{tabular}

TABLE IV. FUZZY RULES OF $\triangle \mathrm{IM}$

\begin{tabular}{|c|c|c|c|c|c|c|c|c|}
\hline \multirow{2}{*}{ tc } & \multicolumn{7}{|c|}{$\boldsymbol{P}_{\max }$} \\
\cline { 2 - 9 } & NB & NM & NS & NZ & PZ & $\boldsymbol{P S}$ & $\boldsymbol{P M}$ & $\boldsymbol{P B}$ \\
\hline NB & PB & PM & PS & PZ & - & - & - & - \\
\hline NM & PM & PM & PS & PZ & - & - & - & - \\
\hline NS & PS & PS & PS & PZ & - & - & - & - \\
\hline NZ & PZ & PZ & PZ & PZ & - & - & - & - \\
\hline PZ & - & - & - & - & NZ & NZ & NZ & NZ \\
\hline PS & - & - & - & - & NZ & NS & NS & NS \\
\hline PM & - & - & - & - & NZ & NS & NM & NM \\
\hline PB & - & - & - & - & NZ & NS & NM & NB \\
\hline
\end{tabular}

\section{Realization of Fuzzy Optimization}

The fuzzy algorithm is realized on MATLAB/simulink software. The MATLAB/simulink environment can call the function block of GT-Power. Then the co-simulation is carried out between MATLAB/simulink software and GT-POWER software as shown in Figure 9. The data exchange cycle is set to one second. If the optimization results can meet the conditions in (13) and (14) simultaneously in 5 consecutive iterations, it is considered to be converged.

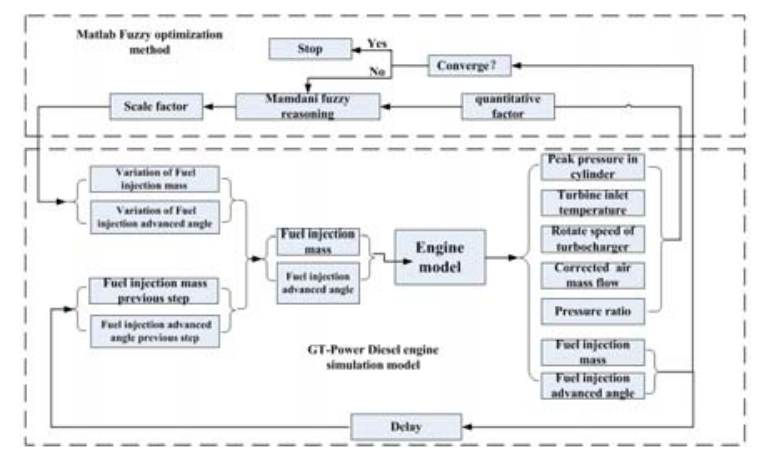

FIGURE IX. SCHEMATIC OF COUPLING SIMULATION.

$\Delta I T<0.001^{\circ} \mathrm{CA}$

$\Delta I M<0.001 m g$

\section{RESULTS AND ANALYSIS}

\section{A. Optimization Process}

Figure 10 shows the fuzzy optimization process of the full load point at $4000 \mathrm{~m}$ altitude, $2100 \mathrm{r} / \mathrm{min}$. There are four initial values a, b, c, d distributing in area A, B, C, D respectively. The simulation results show that no matter where the initial value distributes, the result can converge to the optimum point, which indicates that the optimization method is effective. 


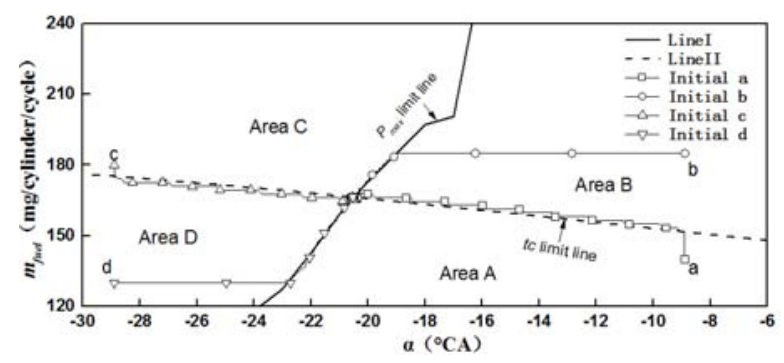

FIGURE X. OPTIMIZATION PROCESS.

\section{B. Optimization Results}

Table. 5 shows comparison between the optimization results and original experiment data of the full load point at $4000 \mathrm{~m}$ altitude, $2100 \mathrm{r} / \mathrm{min}$. Through optimization, the $p_{\max }$ and $T_{e x}$ have all reached their limits; the optimized injection timing is $17^{\circ} \mathrm{CA}$ earlier than that of the original; the optimized injection mass is $18.9 \mathrm{mg}$ more than that of the original. The rate power is increased to $297.9 \mathrm{kw}$, while it is $245 \mathrm{kw}$ for the original engine. The brake specific fuel economy $(B S F C)$ is decreased from $233.5 \mathrm{~g} /(\mathrm{kw} \cdot \mathrm{h})$ to $211.1 \mathrm{~g} /(\mathrm{kw} \cdot \mathrm{h})$.

TABLE V. COMPARISON BETWEEN OPTIMIZATION RESULTS AND ORIGINAL AT 4000M, $2100 \mathrm{R} / \mathrm{MIN}$

\begin{tabular}{|c|c|c|c|}
\hline \multirow{2}{*}{ Parameters } & \multicolumn{3}{|c|}{ Comparison value } \\
\cline { 2 - 4 } & Original & Optimization & Variations \\
\hline$\alpha\left({ }^{\circ} \mathrm{CA}\right)$ & -5.44 & -20.5 & -15.06 \\
\hline$m_{\text {fue }} / \mathrm{mg}$ & 147.5 & 166.4 & 18.9 \\
\hline Rate power $/ \mathrm{kw}$ & 245 & 297.9 & 52.9 \\
\hline$B S F C / \mathrm{g} /(\mathrm{kw} \cdot \mathrm{h})$ & 233.5 & 211.1 & -22.4 \\
\hline$P_{\max } / \mathrm{MPa}$ & 9.56 & 14.50 & 4.94 \\
\hline$n / \mathrm{r} / \mathrm{min}$ & 99900 & 100000 & 100 \\
\hline$T_{e x} /{ }^{\circ} \mathrm{C}$ & 675 & 656.3 & -18.7 \\
\hline$S$ & 3.74 & 3.81 & 0.07 \\
\hline
\end{tabular}

\section{CONCLUSIONS}

In this paper, a fuzzy optimization method is proposed to calibrate the fuel injection parameters of the diesel engine working under plateau conditions. The diesel engine simulation model is built with a zero dimension predictable combustion model. The main results are summarized as follows:

- Fuzzy optimization method is proposed based on the fuzzy logic controller and is used to calibrate the fuel injection parameters.

- Engine performance of the full load point at $2100 \mathrm{r} / \mathrm{min}$ has a significant improvement compared to that of the original engine. The maximum brake power has been increased by $21 \%$. The brake specific fuel consumption is decreased by $10 \%$.

\section{ACKNOWLEDGMENT}

The research is supported by National Science Foundation of China (grant NO.51475043).

\section{REFERENCES}

[1] Jiang Ze hao, Zhang Fu jun, Dong Chang long, et al. Experimental study on performance of turbocharged diesel engine on plateau[J]. Vehicle Engine, 6(2014) 59-63. (in Chinese )

[2] YAO Chun-de, Dai Qian, Xu Han jun, Zhuang Yuan, Yang Guang feng, Ignition and Combustion Characteristics of Diesel Spray in Premixed Methanol/Air Mixture with High Temperature[J]. Journal of Combustion Science and Technology, 18(2012) 199-205. (in Chinese )

[3] Zhu Z, Zhang F, Li C, et al. Calibration for Fuel Injection Parameters of the Diesel Engine Working at Plateau via Simulating[J]. Advances in Mechanical Engineering, 2014:1-8.

[4] Zhang H, Zhuge W, Zhang Y, et al. Study of the Control Strategy of the Plateau Self-adapted Turbocharging System for Diesel Engine[C]// Sae International Powertrains, Fuels and Lubricants Congress. 2008.

[5] Xu Hua ping, Shi Yan feng, et al. Optimization of Injection Advance Angle and Performance Research of Turbocharged Diesel Engine at High Altitude[J], Chinese Internal Combustion Engine Engineering,36(2015) 118-123. (in Chinese )

[6] Zhu Z X, Zhang F J, Han K, et al., Adaption of fuel injection parameters for turbocharged diesel engines working at high altitude, Binggong Xuebao/acta Armamentarii. 35 (2014) 583-589.

[7] Li C, Zhao Chang lu, Zhang F, Zhu Z. Optimization of Diesel Injection Strategies at Plateau with Genetic Algorithm and Study of Penalty Parameters[J]. Transactions of Csice, 33(2015):250-256.

[8] Zhu Z, Zhang F, Li C, et al. Genetic algorithm optimization applied to the fuel supply parameters of diesel engines working at plateau $i\}[\mathrm{J}]$. Applied Energy, 2015, 157:789-797.

[9] Harris C J, Brown M, Moore C G. Intelligent Control: Aspects of Fuzzy Logic and Neural Nets[M]. World Scientific, 1993.

[10] Su H, Gang H, Li P, et al. Feed forward Fuzzy PID Controller for Common-rail Pressure Control of Diesel Engine[C]// International Conference on Measuring Technology and Mechatronics Automation. IEEE, 2010:264-267.

[11] Wang Zhong, Yuan Yin nan, et al. Electronically Controlled Injection System for LPG/Diesel Dual-fuel Engine Based on Fuzzy Algorithm[J], Transactions of the Chinese Society for Agricultural Machinery, 36(2005) 27-30.

[12] Ma Bin, Chen Yong, Gong Guo qing. Study on Fuzzy Control of Driving Antiskid for Four-wheel Drive Electric Vehicle [J], Computer Simulation, 33(3016) 144-148+185.

[13] Xin Zhe, Li Ya ping, Zhang Yun long, et al. Fuzzy control and experiment of rail pressure for high- pressure common rail system of diesel engine $[\mathrm{J}]$, Transactions of the Chinese Society of Agricultural Engineering, 32(2016) 34-41

[14] Zhu Ying he, Xue Ling yun, Huang Wei. Design of Fuzzy PID Controller Based on Self-organizing Adjustment Factors[J], Journal of System Simulation, 23(2011) 2732-2737.

[15] Song Chun jie, He Zhi tong ,et al. Vehicle Handling Stability Analysis Based on PID and Fuzzy Logic Control[J], Energy Conservation \& Environmental Protection in Transportation, 2(2016) 21-26+34.

[16] Wu T, Zhao C, Han K, et al. Control-Oriented Modeling of Turbocharged Diesel Engines Transient Combustion Using Neural Networks[J], Sae Technical Papers, 2014, 1.

[17] Zhu Z X, Zhang F J, Wu T T, et al. Zero-D predictable combustion model based on neural network and modeling $[\mathrm{J}]$, Transactions of Csice, 33(2015) 163-170. 